\title{
The effects of foot reflexology on pain and physiological indicators in children with leukemia under chemotherapy: a clinical trial study
}

\author{
Fereshteh Ghaljaei ${ }^{1}$, Alia Jalalodini ${ }^{2}$ \\ ${ }^{1}$ Department of Pediatric Nursing, School of Nursing and Midwifery, Community Nursing Research Center, \\ Zahedan University of Medical Sciences, Zahedan, Iran \\ ${ }^{2}$ Department of Nursing, School of Nursing and Midwifery, Zahedan University of Medical Sciences, Zahedan, Iran
}

\begin{abstract}
Background: Foot reflexology is a popular complementary medicine method; however, previous studies have shown conflicting results. This study aimed to investigate the impact of foot reflexology on pain and physiological responses caused by intrathecal injection of chemotherapy drugs in children with leukemia.

Materials and methods: This clinical trial included 80 children with leukemia. The participants received 20 min foot reflexology (10 min each foot). The primary measured outcomes included pain and physiological indicators (blood pressure and heart rate).

Results: The results showed that foot reflexology had a significant effect on reducing pain $(p=0.002)$ and improving physiological indicators [blood pressure $(p=0.002)$ and heart rate $(p=0.003)$ ].

Conclusion: Based on the results of the present study, which shows the positive effect of foot reflexology on the improvement of pain and physiological indicators, foot reflexology can be used as a complementary treatment along with conventional therapies.
\end{abstract}

Key words: reflexology; pain; children; leukemia

Rep Pract Oncol Radiother 2021;26(6):955-961

\section{Introduction}

Leukemia, one of the most important types of cancer as a public health challenge, is the most common type of pediatric cancers. Common leukemia types include acute lymphoblastic leukemia (ALL) and chronic lymphocytic leukemia (CLL) [1]. According to the latest report on the global burden of disease study in 2020, the global prevalence of ALL and CLL among children was $12.4 \%$ and $17.6 \%$, respectively. In addition, evidence shows that leukemia is more prevalent in Asia [2]. According to the latest GLOBOCAN statistics, there are more than 474,519 patients with leukemia in Iran [3].

Despite many advances in the treatment of leukemia, there is no definitive cure. Therefore, the most important goal is to prevent the progression of the disease, relieve the side effects of treatments, and improve the quality of life of patients [4]. Leukemia treatments include surgery, biological therapies (including immunotherapy and gene therapy),

Address for correspondence: Alia Jalalodini, Hesabi St, Zahedan University of Medical Sciences, Zahedan, Iran, fax: +98-5435223101; e-mail: a_jalalodini@yahoo.com 
and chemotherapy [5]. Chemotherapy uses cytotoxic drugs that can be used to treat and relieve symptoms [6]. Chemotherapy is administered in several ways, including oral, intravenous, catheter, and intrathecal (IT) injection of cerebrospinal fluid [7]. Physical and psychological complications of chemotherapy in patients cause fear of starting chemotherapy and even resistance or rejection of anti-cancer treatment programs [8]. Additionally, it incurs high costs for patients and prolongs the hospital stay, and reduces the quality of life and performance of patients [9]. Pain is the most common and annoying experience in patients with leukemia [10]. Uncontrolled pain in children leads to the involvement of the cardiovascular, pulmonary, gastrointestinal, and immune systems [11]. Pain relief is one of the most challenging aspects of patient care in cancer [12].

Complementary and alternative medicine (CAM) have been introduced in recent years as an effective and popular method for pain relief in chronic diseases [13]. Such methods lead to a reduction in the use of analgesics and opioids, which have side effects such as respiratory problems, addiction, and dependence [14]. The use of CAM therapies increases the patient's ability to adapt and reduce their anxiety and can be easily used by children. Additionally, it is accompanied by easy acceptance and cooperation between children and parents [15]. Among these methods, foot reflexology is a type of massage, which is one of the most important complementary therapies used among nurses [16]. Different studies have shown that reflexology improves the symptoms of appendectomy [17], and cancer pain [18], and some physiological symptoms in children [19]. However, some studies have shown that reflexology has no significant effect on improving physiological parameters [20]. Despite these studies, their results are contradictory with very few studies, particularly on school children; therefore, more studies are needed in this field. Therefore, this study aimed to investigate the effect of foot reflexology on pain and physiological indicators during chemotherapy in children with leukemia.

\section{Materials and methods}

\section{Design and participants}

This clinical trial study was performed on 80 school-age children (aged 6-12 years) with leuke- mia admitted to the hematology ward of a teaching hospital in Zahedan from February 1, 2020, to December 20, 2020. The inclusion criteria were as follows: leukemia and prior IT administration of chemotherapy. Exclusion criteria were: unwillingness to participate, child restlessness, seizures, heart disease, and acute respiratory disease. The participants received analgesics or sedatives before the intervention. Based on Unesi et al. study, the sample size was determined with a $95 \%$ confidence interval and statistical test power of $80 \%$, and 22.38 participants were calculated in each group. To prevent samples from falling during the data collection process, the sample size in each group was estimated to be 40 participants with a total of 80 participants [21].

\section{Instrument}

The data collection tool included three parts: demographic characteristics, physiological indicators, and the OUCHER pain measurement tool. Demographic characteristics included age, sex, education of the child, frequency of IT chemotherapy drugs, and duration of the disease. Physiological indicators included heart rate (HR), systolic blood pressure (SBP), and diastolic blood pressure (DBP). The OUCHER is a standard pain instrument that is suitable for children. In this tool, photographs of normal and upset faces of children are used, which are taken of children while experiencing real pain in the hospital. This tool includes six pictures of children demonstrating different degrees of pain and are placed vertically from the least to the most severe pain from the bottom up, having scores of $1-6$, where 1 indicates no pain and 6 indicates very severe pain. For children who are unable to count to 100 , a score of 1 indicates no pain; 2 , mild pain; 3 and 4, moderate pain; 5 , severe pain; and 6 , the most severe pain experienced by the child. The numbers $0-100$ are also placed to the left of the photographs. The numerical value is for children who can count with zero being painless; $1-29$, mild pain; 30-69, moderate pain; 70-99, severe pain; and 100 , the most severe pain possible. In the present study, a numerical format of $0-100$ Osher tools was used [22]. A Q\&Q stopwatch manufactured in China was used to measure the duration of injection of IT chemotherapy drugs with an accuracy of one-hundredth of a second. In addition, a digital arm sphygmomanometer model PG800B10 with a pedal prop was used to measure blood pressure. 


\section{Intervention}

First, the objectives of the study were explained to the patients' parents. They were available to all patients who met the inclusion criteria. Then, based on a simple random method, envelopes containing cards with numbers one and two were given to the participants. Patients selecting number one were placed in the intervention group, while those selecting two were placed in the control group. Sampling was performed every other week. In the first week, by drawing lots, the samples were placed in the intervention or control group, and in the next week, they were examined in the control group. In the intervention group, foot reflexology was performed by a researcher with 5 years of experience. Simultaneous validity was used to obtain the correct determination of the reflection points of the foot and how to apply pressure; thus, the method of work was approved by the acupuncturist and expert in reflexology. Before the intervention, the researcher prepared the patient and environment for the intervention. The demographic information questionnaire was completed before foot reflexology. All patients were provided towels and shampoos to wash their feet. The patient was made to lie on their back. A pillow was placed under the patient's foot, and their trousers were pulled up to the knee. The researcher sat in a completely comfortable and relaxed position in front of the patient. The researcher smeared his hand with a small amount of baby lotion with non-therapeutic properties. For general massage, the massage was initiated from the calf. The soles of the feet and toes were massaged successively for $2 \mathrm{~min}$ for relaxation. Special attention was paid to four important reflection points of the sole, namely the solar plexus, pituitary gland, heart, and liver. The solar plexus is located between the upper and middle third of the sole and the area between the heart and liver under the chest, which is mostly used as a reflection point for vital signs, while the pituitary gland is located in the middle of the big toe. Each of the reflection points of the foot using the middle part of the first part of the index finger and the fleshy part of the toe of the researcher, with a pressure of $0.5 \mathrm{~cm}$ were massaged circularly; thus, one-third of the nail bed was white, without interrupting the contact of the toes with the foot skin. The reflective massage was performed with constant pressure in the form of continuous and rotational clockwise movements in each part. After finishing one foot, the sole of the other foot was reflected in the same manner. First, the massage was performed on the left foot then on the right foot. A total of $10 \mathrm{~min}$ of reflexology massage was performed for each foot with a total of $20 \mathrm{~min}$ for both feet (68). To check the physiological parameters, blood pressure of all children was measured in the right hand using a sphygmomanometer. The heartbeat was examined for $1 \mathrm{~min}$ to assess HR. After 20 min of massage, the child was transferred to the IT room. Ten minutes after IT, the researcher assisted the child by observing their pain and examining their physiological parameters. Simultaneously, the child's pain intensity was completed with the child's report using the Osher pain tool. The totality of the measures performed and the examination of pain and physiological features were performed once. Additionally, all IT injections of chemotherapy drugs were administered by a physician. In the control group, routine treatment and care were performed 20 min before IT drug injection, and at specified times (10 min after IT) physiological indicators and pain were assessed as in the intervention group. This study was performed in a blinded manner. In this way, a research assistant who had the characteristics of a researcher was used to evaluate physiological parameters and pain after the intervention. The researcher assisted had no information about the samples or groups (Fig. 1,2).

\section{Ethical considerations}

This study was approved by the committee of ethics at the Zahedan University of Medical Sciences (IR.ZAUMS.REC.1398.169), also the protocol of study Registry code in the Iranian clinical trial registry center (IRCT20121025011261N3). Written and oral consent was obtained from all participants in the study. Participants were assured that their information would remain confidential. The CONSORT checklist was used to report the study [23]

\section{Data analysis}

Data were analyzed using SPSS v.18 (SPSS, Chicago, IL) and Chi-square, independent, and paired t-test samples. The $\chi^{2}$ test was used to control for qualitative demographic variables. The t-test was performed to compare the means of pain and physiological parameters after the intervention in each group and between the two groups. A Kolmogorov-Smirnov test was used to check for normal dis- 


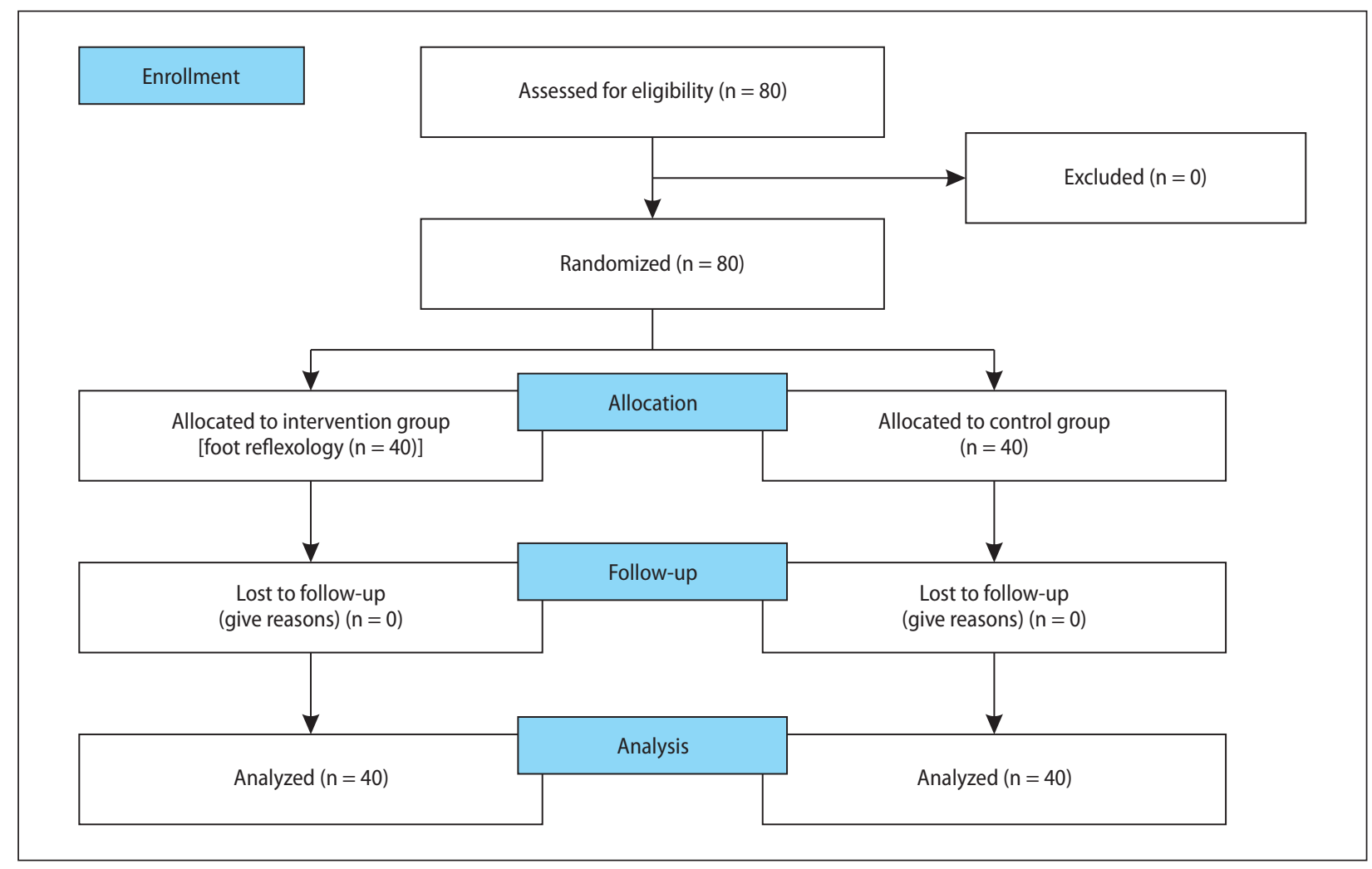

Figure 1. CONSORT 2010 flow diagram

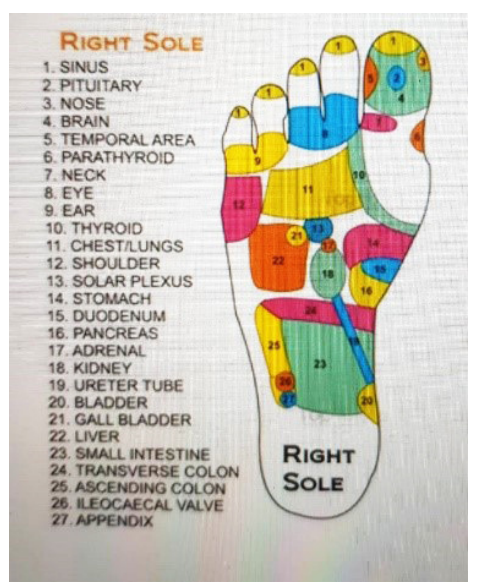

Figure 2. Foot reflexology chart

tribution. Data are presented as mean \pm standard deviation (SD). Statistical significance was set at $\mathrm{p}<0.05$.

\section{Results}

Findings showed that the mean age of the children in the intervention group was $(8.06 \pm 2.10)$ years, and control group was $(8.58 \pm 2.87)$ years.
Table 1 shows the main characteristics of both groups. The main demographic characteristics were not significantly different between the two groups ( $\mathrm{p}>0.05)$ (Tab. 1).

Table 2 shows that the means of SBP and DBP after intervention in the intervention group were $88.32 \pm 16.58 \mathrm{mmHg}$ and $55.95 \pm 12.7 \mathrm{~mm} \mathrm{Hg}$, respectively. However, the means of SBP and DBP after intervention in the control group were $95.48 \pm 14.26 \mathrm{~mm} \mathrm{Hg}$ and $56.62 \pm 10.31 \mathrm{mmHg}$, respectively. The independent t-test showed that the mean of SBP and DBP after intervention between the two groups were $\mathrm{p}<0.0001$ and $\mathrm{p}=0.002$, respectively.

The mean HR after intervention in the intervention and control group was $90.45 \pm 15.1$ and $95.8 \pm 10.5$, respectively. The independent t-test showed a significant difference in the mean $\mathrm{HR}$ after intervention between the two groups $(\mathrm{p}=0.003)$.

The mean pain after intervention in the intervention and control group was $35.11 \pm 14.71$ and $42.50 \pm 16.44$. The independent $t$-test showed that the mean pain intensity was significantly lower in the intervention group than in the control group $(\mathrm{p}=0.02)($ Tab. 2). 
Table 1. The main characteristics studied in both groups

\begin{tabular}{|c|c|c|c|}
\hline Variables & $\begin{array}{l}\text { Intervention group } \\
\qquad(\mathrm{n}=40)\end{array}$ & $\begin{array}{l}\text { Control group } \\
\qquad(n=40)\end{array}$ & p-value \\
\hline Age (mean $\pm S D)$ & $8.06 \pm 2.10$ & $8.58 \pm 2.87$ & $0.41^{\mathrm{a}}$ \\
\hline \multicolumn{4}{|l|}{ Gender } \\
\hline Male & $24(53.3)$ & $25(56.8)$ & \multirow[b]{2}{*}{$0.74^{b}$} \\
\hline Female & $16(46.7)$ & $15(42.2)$ & \\
\hline \multicolumn{4}{|c|}{ Duration of leukemia } \\
\hline$\leq 2.5$ & $6(15)$ & $4(10)$ & \multirow[b]{2}{*}{$0.09^{\mathrm{b}}$} \\
\hline $2.5-5$ & $32(80)$ & $34(86)$ & \\
\hline$>5$ & $2(5)$ & $2(4)$ & \\
\hline \multicolumn{4}{|c|}{ Birth orders (n, \%) } \\
\hline $1-2$ & $16(40)$ & $23(57.5)$ & $0.08^{\mathrm{a}}$ \\
\hline $3-4$ & $24(60)$ & $17(42.5)$ & \\
\hline
\end{tabular}

SD - standard deviation; ${ }^{a}$ t-test; ${ }^{b} \chi^{2}$ test

Table 2. Changes of means in heart rate (HR), systolic blood pressure (SBP) and diastolic blood pressure (DBP) after intervention in both groups

\begin{tabular}{|c|c|c|c|}
\hline Variables & Intervention $(n=40)$ & Control $(n=40)$ & $p$ (t-test) ${ }^{a}$ \\
\hline SBP & $88.32 \pm 16.58$ & $95.48 \pm 14.26$ & $<0.0001^{*}$ \\
\hline DBP & $55.95 \pm 12.7$ & $56.62 \pm 10.3$ & $0.002^{*}$ \\
\hline $\mathrm{HR}$ & $90.45 \pm 15.1$ & $95.8 \pm 10.5$ & $0.003^{*}$ \\
\hline The pain & $35.11 \pm 14.71$ & $42.50 \pm 16.44$ & $0.02 *$ \\
\hline
\end{tabular}

an independent sample t-test, ${ }^{*} \mathrm{p}<0.05$

\section{Discussion}

Currently, the use of CAM methods to relieve symptoms in chronic incurable patients is increasing daily. This study aimed to evaluate the effect of foot reflexology on pain and physiological indicators in children receiving IT injections of chemotherapy. The results of the present study showed that foot reflexology significantly reduced pain. The results of the present study are in line with those of previous studies in patients with appendectomy [17], surgical [24], labor [25], and rheumatoid arthritis pain [26], all of which indicate a positive effect of foot reflexology on pain relief. The results also showed that foot reflexology caused significant changes in the physiological indices of HR and blood pressure. The results of the present study are consistent with those of previous studies on children with leukemia [19] and adults undergoing open-heart surgery [27], those with bronchoscopy [28], and in the intensive care unit [29]. The high impact of foot reflexology can be attributed to the presence of many nerves in the foot. In contrast to the present study, the results of studies by Jazayeri et al. [20] and Samadi et al. [30] showed that foot reflexology had no significant effect on HR. This difference may be owing to the sample size and, more importantly, the target population in the two studies. In the present study, the participants were children aged 3-12 years; however, the previous studies included neonatal participants whose differences in response to foot reflexology were different [20,30]. Padial et al. (2012) also stated that foot reflexology massage increased children's anxiety and physiological parameters. They believed that foot reflexology stimulates the sympathetic and parasympathetic nervous systems; thus, increasing the HR. The results of this study are inconsistent with those of the present study [31]. The results of the study by Khazaei et al. (2019) showed that foot reflexology twice a day for 2 weeks could reduce the rate of neuropathic pain in women with cancer, undergoing chemotherapy [32]. 


\section{Limitations and strengths}

One of the limitations of the present study was the limited attitude of the indigenous people of the region towards touch and massage, which made it possible to resist the practice of foot reflexology. Another limitation was the lack of time coordination between the researcher performing reflexology and the physician performing IT. Another limitation is the small sample size of the study, possibly making it challenging to generalize the results. Despite these weaknesses, this clinical trial was one of the first studies to be performed on school-age children with leukemia in this region of the country.

\section{Conclusion}

The results of the present study showed that reflexology, as a method of distraction in children, could reduce pain during IT and was effective on physiological parameters after IT. Therefore, this method should be implemented as a low-cost intervention by nurses and other health groups to reduce pain during IT procedures. As few studies exist in this regard, more studies should be conducted to investigate other methods of distraction on the pain caused by IT in children.

\section{Conflict of interest}

The authors declare that they have no conflict of interest.

\section{Funding}

None declared.

\section{References}

1. Kantarjian HM, Kadia TM, DiNardo CD, et al. Acute myeloid leukemia: Treatment and research outlook for 2021 and the MD Anderson approach. Cancer. 2021; 127(8): 1186-1207, doi: 10.1002/cncr.33477, indexed in Pubmed: 33734442.

2. Dong $Y$, Shi O, Zeng $Q$, et al. Leukemia incidence trends at the global, regional, and national level between 1990 and 2017. Exp Hematol Oncol. 2020; 9: 14, doi: 10.1186/ s40164-020-00170-6, indexed in Pubmed: 32577323.

3. Globocan (2021) Cancers in Iran https://gco.iarc.fr/today/ online-analysis-table? $v=2020 \&$ mode $=$ cancer\&mode_po pulation $=$ continents $\&$ population $=900 \&$ population $\mathrm{s}=364 \&$ key $=$ asr \&sex $=0$ \&cancer $=39$ \&type $=0$ \& statis tic $=5 \&$ prevalence $=0 \&$ population_group $=0 \&$ ages_ group $\% 5 \mathrm{~B} \% 5 \mathrm{D}=0 \&$ ages_group $\% 5 \mathrm{~B} \% 5 \mathrm{D}=17$ \&group_ cancer $=1$ \&include_nmsc $=1$ \&include_nmsc_other $=1$..

4. Bramati $P$, Hui D, Bruera E. Integrated Palliative and Oncology Care for Patients With Acute Myeloid Leukemia-
Moving From Evidence to Practice. JAMA Oncol. 2021; 7(6): 943, doi: 10.1001/jamaoncol.2021.0706, indexed in Pubmed: 33885730.

5. Estey E. New treatments for acute myeloid leukemia: how much has changed? Leukemia. 2021; 35(1): 45-46, doi: 10.1038/s41375-020-01084-2, indexed in Pubmed: 33184492.

6. Locatelli F, Zugmaier G, Rizzari C, et al. Effect of Blinatumomab vs Chemotherapy on Event-Free Survival Among Children With High-risk First-Relapse B-Cell Acute Lymphoblastic Leukemia: A Randomized Clinical Trial. JAMA. 2021; 325(9): 843-854, doi: 10.1001/jama.2021.0987, indexed in Pubmed: 33651091.

7. de Kruif AJ, Westerman MJ, Winkels RM, et al. Exploring changes in dietary intake, physical activity and body weight during chemotherapy in women with breast cancer: A Mixed-Methods Study. J Hum Nutr Diet. 2021; 34(3): 550-561, doi: $10.1111 /$ jhn.12843, indexed in Pubmed: 33411940.

8. Ai YT, Hu H, Yang CM, et al. Hindrances of peripherally inserted central catheter care of leukemia patients: a qualitative study. Support Care Cancer. 2021; 29(8): 4339-4347, doi: 10.1007/s00520-020-05941-9, indexed in Pubmed: 33409725.

9. Forsythe A, Sandman K. What Does the Economic Burden of Acute Myeloid Leukemia Treatment Look Like for the Next Decade? An Analysis of Key Findings, Challenges and Recommendations. J Blood Med. 2021; 12: 245-255, doi: 10.2147/JBM.S279736, indexed in Pubmed: 33981169.

10. Damayanti R, Allenidekania A. The correlation between the quality of pain and fatigue in children with acute lymphoblastic leukemia (ALL). Enfermer Clín. 2021; 31: S330-S333, doi: 10.1016/j.enfcli.2020.09.022.

11. Barzilai-Birenboim S, Yacobovich J, Zalcberg Y, et al. Bone pain at leukemia diagnosis and other risk factors for symptomatic osteonecrosis in children with acute lymphoblastic leukemia. Pediatr Blood Cancer. 2021; 68(8): e29033, doi: 10.1002/pbc.29033, indexed in Pubmed: 33788395.

12. Miladinia M, Voss JG, Molavynejad S, et al. Slow-Stroke Back Massage Compared With Music Therapy for Leukemia-Related Pain and Fatigue: A Randomized Controlled Trial. JCO Oncol Pract. 2021 [Epub ahead of print]: OP2100156, doi: 10.1200/OP.21.00156, indexed in Pubmed: 34077243.

13. Ng JY, Sharma AE. Guidelines for Cancer-Related Pain: A Systematic Review of Complementary and Alternative Medicine Recommendations. Pain Pract. 2021; 21(4): 454-467, doi: 10.1111/papr.12964, indexed in Pubmed: 33197300.

14. Zhang C, Xiao J, Yu Z, et al. Cancer pain management and the roles of pharmacists in China. Int J Clin Pharm. 2021; 43(2): 383-385, doi: 10.1007/s1 1096-021-01230-5, indexed in Pubmed: 33439424.

15. Ciarlo G, Ahmadi E, Welter S, et al. Factors influencing the usage of complementary and alternative medicine by patients with cancer. Complement Ther Clin Pract. 2021; 44: 101389, doi: 10.1016/j.ctcp.2021.101389, indexed in Pubmed: 33932731.

16. Huang HC, Chen KH, Kuo SF, et al. Can foot reflexology be a complementary therapy for sleep disturbances? Evidence appraisal through a meta-analysis of randomized controlled trials. J Adv Nurs. 2021; 77(4): 1683-1697, doi: 10.1111/jan.14699, indexed in Pubmed: 33615535. 
17. Taheri $\mathrm{H}$, Naseri-Salahshour V, Abedi A, et al. Comparing the Effect of Foot and Hand Reflexology on Pain Severity after Appendectomy: A Randomized Clinical Trial. Iran J Nurs Midwifery Res. 2019; 24(6): 451-456, doi: 10.4103/ ijnmr.IJNMR_85_18, indexed in Pubmed: 31772920.

18. Singh P, Chaturvedi A.Complementary and alternative medicine in cancer pain management: a systematic review. Indian J Palliat Care. 2015; 21 (1): 105-115, doi: 10.4103/09731075.150202, indexed in Pubmed: 25709198.

19. Ghazavi A, Pouraboli B, Sabzevari S, et al. Evaluation of the effects of foot reflexology massage on vital signs and chemotherapy-induced anxiety in children with leukemia. Med-Surg Nursing J. 2016; 4(e68081).

20. Jazayeri Z, Sajadi M, Dalvand H, et al. Comparison of the effect of foot reflexology and body massage on physiological indicators and bilirubin levels in neonates under phototherapy. Complement Ther Med. 2021; 59: 102684, doi: 10.1016/j.ctim.2021.102684, indexed in Pubmed: 33609634.

21. Unesi Z, Izadpanah AM, Farajzadehe Z, et al. Impact of Distraction Technique on Reducing the Infants' Vaccination Pain. Modern Care J. 2014; 11(1): 1-9.

22. Beyer JE, Denyes MJ, Villarruel AM. The creation, validation, and continuing development of the Oucher: a measure of pain intensity in children. J Pediatr Nurs. 1992; 7(5): 335-346, indexed in Pubmed: 1479552.

23. Schulz KF, Altman DG, Moher D, et al. CONSORT Group. CONSORT 2010 Statement: updated guidelines for reporting parallel group randomised trials. Trials. 2010; 11: 32, doi: 10.1186/1745-6215-11-32, indexed in Pubmed: 20334632.

24. Hudson BF, Davidson J, Whiteley MS. The impact of hand reflexology on pain, anxiety and satisfaction during minimally invasive surgery under local anaesthetic: a randomised controlled trial. Int J Nurs Stud. 2015; 52(12):
1789-1797, doi: 10.1016/j.ijnurstu.2015.07.009, indexed in Pubmed: 26294281.

25. Dolatian M, Hasanpour A, Heshmat R, et al. The effect of reflexology on pain intensity of labor. J Adv Med Biomed Res. 2010; 18(72): 52-61, indexed in Pubmed: 22737514.

26. Taha NM, Ali ZH. Effect of reflexology on pain and quality of life in a patient with rheumatoid arthritis. Marsland Press, Newburgh 2011:357-365.

27. Elsayed AE, Kandeel NA, El-Aziz WW. The Effect of Foot Reflexology on Physiological Indicators and Mechanical Ventilation Weaning Time among Open-Heart Surgery Patients. Am J Nurs Res. 2019; 7(4): 412-419, doi: 10.12691/ ajnr-7-4-2.

28. Shahsavari $\mathrm{H}, \mathrm{Abad} M$, Yekaninejad $M$. The effects of foot reflexology on anxiety and physiological parameters among candidates for bronchoscopy: A randomized controlled trial. Eur J Integrat Med. 2017; 12: 177-181, doi: 10.1016/j.eujim.2017.05.008.

29. Sheikh S, Yaghoubinia F, Navidian A. Impact of Foot Reflexology Massage on the Patients' Physiological Indicators without Trauma with Loss of Consciousness in the Intensive Care Unit. Indian J Publ Health Res Dev. 2017; 8(2): 201, doi: 10.5958/0976-5506.2017.00111.5.

30. Samadi N, Allahyari I, Mazaheri E, et al. Effect of foot reflexology on physiologic index of neonates. Iranian J Neonatol. 2014; 5(1): 19-22.

31. Padial ER, López NT, Bujaldón JL, et al. Cardiovascular effects of reflexology in healthy individuals: evidence for a specific increase in blood pressure. Alternative Med Stud. 2012; 2(1): 4, doi: 10.4081/ams.2012.e4.

32. Khazaei T, Rezaei Mo, Sebzari AR, et al. The effect of foot reflexology massage on the stress and neuropathic pain caused by chemotherapy in women with breast cancer and genitalia. J Birjand Univ Med Sci. 2019; 26(1): 4-12, doi: 10.32592/jbirjandunivmedsci.2019.26.1.101. 